\title{
De hik als vroeg symptoom bij COVID-19
}

Jannet Knijp, Floor Prins

COVID-19 kan uiteenlopende klachten veroorzaken. Wij zagen een patiënt met persisterende hik als enige symptoom van wat uiteindelijk een ernstige SARS-CoV-2-infectie bleek te zijn. De differentiaaldiagnose bij persisterende hik is breed en de diagnostiek kan lastig zijn.

De hik is een myoklonische contractie van het diafragma. De gedachte is dat de hik ontstaat vanuit een reflexboog die uit 3 componenten bestaat: afferente zenuwbanen (nervus vagus, nervus phrenicus en het thoracale deel van het sympathische zenuwstelsel), het hikcentrum (onderdeel van het centrale zenuwstelsel) en efferente zenuwbanen (voornamelijk de nervus phrenicus). De hik ontstaat wanneer een van de componenten van deze reflexboog wordt gestimuleerd, met als resultaat een contractie van het diafragma en meestal ook van de intercostale spieren. Het kenmerkende geluid komt door het sluiten van de glottis als reflex op het inademen van lucht. ${ }^{1}$ Meestal is de hik het gevolg van maagdilatatie, zoals na inna-

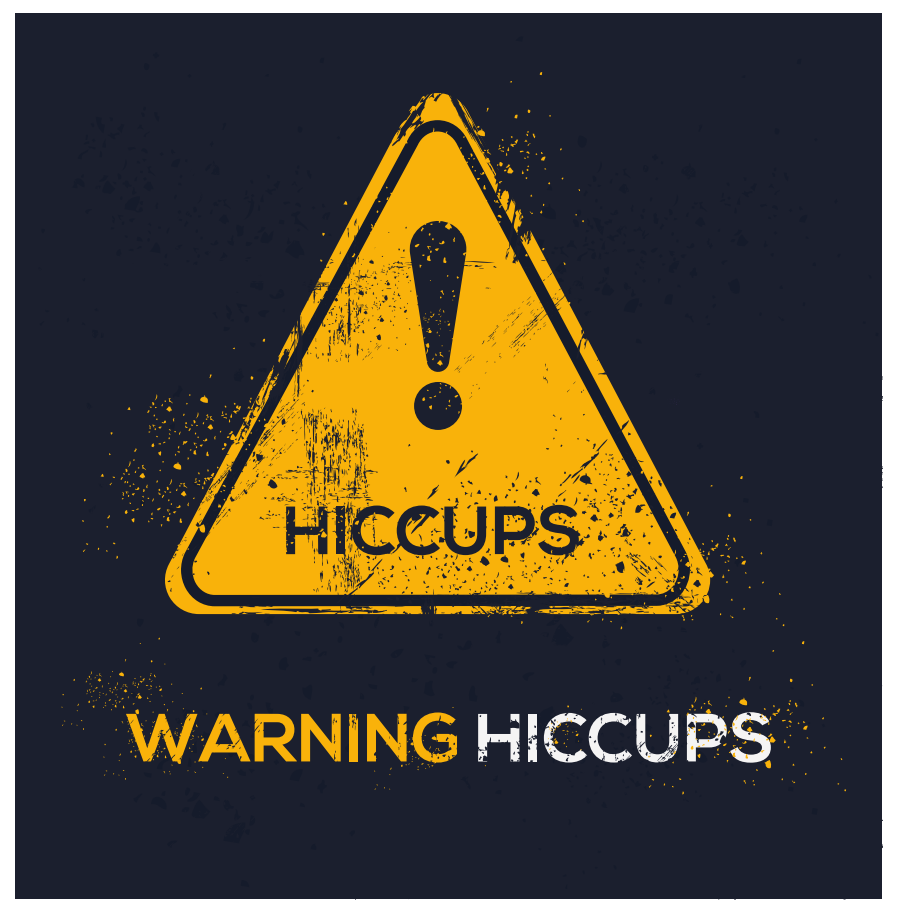

Een associatie tussen COVID-19 en de hik is niet uit te sluiten, maar het is onduidelijk wat het verband precies is.
Foto: Shutterstock

\begin{abstract}
CASUS: EEN 63-JARIGE MAN MET EEN HINDERLIJKE HIK
Een 63-jarige man neemt per telefoon contact op met de huisartsenpraktijk vanwege een hinderlijke hik die al meer dan 48 uur persisteert en die ook's nachts aanhoudt. Hij heeft geen bijkomende klachten. Zijn medische voorgeschiedenis bestaat uit hypertensie, een longembolie en een hernia diaphragmatica. Als medicatie gebruikt hij amlodipine, metoprolol, rivaroxaban en pantoprazol. Een dag ervoor is op de huisartsenpost al lichamelijk onderzoek verricht, waarbij geen afwijkende bevindingen werden gevonden. De huisarts geeft tijdens het telefonisch consult een recept voor baclofen in een opbouwende dosering, maar dit heeft geen effect.

Enige dagen later, een week na het ontstaan van de klacht, ziet de huisarts de patiënt vanwege ernstige dyspneu en zwakte. Nog dezelfde dag wordt de patiënt opgenomen op de intensivecareafdeling vanwege een SARS-CoV-2-infectie met respiratoire insufficiëntie.
\end{abstract}

me van koolzuurhoudende dranken of een grote maaltijd, en gaat hij vanzelf over. Wanneer de klachten langer dan 48 uur aanhouden, spreekt men van een persisterende hik. ${ }^{1,2}$ Persisterende hik kan een uiting zijn van (ernstige) onderliggende pathologie.

\section{OORZAKEN VAN DE HIK}

De hik kan allerlei oorzaken hebben. Een eerste groep oorzaken betreft het centrale zenuwstelsel, bijvoorbeeld een cerebrovasculair accident, een hersentumor of hersenletsel. Een tweede groep zijn aandoeningen die het perifere zenuwstelsel beïnvloeden via prikkeling van de nervus vagus of de nervus phrenicus. Vaak zijn dit gastro-intestinale aandoeningen - zoals refluxoesofagitis - maar ook cardiovasculaire (pericarditis, aneurysma aortae), pulmonale (pneumonie) of kno-aandoeningen (corpus alienum) kunnen op deze manier een persisterende hik veroorzaken. Belangrijk om niet te missen in dit kader zijn tumoren zoals een oesofagus- of bronchuscarcinoom. Een derde groep zijn de metabole oorzaken, zoals hyperglykemie, uremie en enkele elektrolytstoornissen. Ook van sommige medicamenten (benzodiazepinen, opiaten, steroiden) is bekend dat ze de hik kunnen veroorzaken. Tot slot kan de hik naast de genoemde organische oorzaken ook psychische oorzaken hebben, zoals angst, stress of opwinding. ${ }^{1}$ Bij kankerpatiënten in de palliatieve fase komen hikepisodes relatief veel voor, vaak als gevolg van maagdilatatie of gestoorde maagontlediging door morfine. ${ }^{3}$ In veel gevallen wordt echter geen oorzaak gevonden, men spreekt dan van idiopathische hik. ${ }^{2}$ 


\section{DE KERN}

- Wij zagen een patiënt bij wie persisterende hik aanvankelijk het enige symptoom was van een ernstige SARSCoV-2-infectie.

- Er zijn sporadisch patiënten beschreven bij wie de hik ontstond door een longprobleem.

- Persisterende hik kan een uiting zijn van onderliggende pathologie met een brede differentiaaldiagnose. De diagnostiek kan daardoor een uitdaging zijn.

\section{HET BELOOP VAN ONZE CASUS}

Bij onze patiënt dachten we differentiaaldiagnostisch aan reflux, angst of een maligniteit in longen, maag of slokdarm. Voor de mogelijke reflux werd hij al behandeld met pantoprazol $1 \mathrm{dd} 40 \mathrm{mg}$. We dachten aan angst omdat meneer eerder een hikepisode had doorgemaakt die goed reageerde op oxazepam, maar hij ervoer de huidige episode op een andere manier. Een recente hilaire afwijking op een X-thorax was aanleiding om een pulmonale maligniteit te vermoeden. Deze afwijking bleek bij nadere analyse echter te berusten op een (benigne) vaatstructuur en kon volgens de longarts de hik niet verklaren. Een maligniteit in de maag of slokdarm was minder waarschijnlijk, gezien een niet-afwijkende gastroscopie van 1,5 jaar geleden.

We kozen daarom voor een behandeling met baclofen 3 dd 5 mg volgens de landelijke richtlijn Hik. ${ }^{3} \mathrm{Na} 2$ dagen hoogden we de baclofen op naar $3 \mathrm{dd} 10 \mathrm{mg}$, maar dit had geen effect. De mdl-arts adviseerde de pantoprazol te verdubbelen naar $2 \mathrm{dd} 40 \mathrm{mg}$, zo nodig oxazepam $10 \mathrm{mg}$ toe te voegen en een gastroscopie te verrichten als ook deze medicatie geen effect zou hebben.

Toen de patiënt de volgende dag (7 dagen na het ontstaan van de hik) opnieuw contact opnam vanwege aanhoudende klachten, nodigden we hem uit op consult. De patiënt was bij beoordeling kortademig, suf en veel aan het hoesten, en bij longauscultatie werden crepitaties over alle longvelden gehoord. We stuurden hem door naar de spoedeisende hulp vanwege een vermoeden van een pneumonie, mogelijk op basis van COVID-19.

Op de $\mathrm{SEH}$ was de saturatie $83 \%$, de temperatuur $38,5^{\circ} \mathrm{C}$ en de sneltest op SARS-CoV-2 positief. De patiënt werd opgenomen op de intensivecareafdeling vanwege respiratoire insufficiëntie en dreigende uitputting. De opname duurde 14 dagen.

\section{VERGELIJKBARE PATIËNTEN IN DE LITERATUUR}

De hik als symptoom van COVID-19 is enkele keren beschreven. Voor zover bekend zijn over dit fenomeen 3 case-reports gepubliceerd: 1 uit de Verenigde Staten (april 2020), 1 uit Mexico (juni 2020) en 1 uit Egypte (november 2020). ${ }^{4-6}$ Bij deze 3 patiënten was de hik een vroeg symptoom van een SARS-CoV-2-infectie en bij 2 van hen was de hik aanvankelijk zelfs het enige symptoom. Ze werden alle 3 opgenomen in het ziekenhuis ter (ondersteunende) behandeling van COVID-19, maar hoefden niet naar de intensive care. Een van hen kreeg baclofen 3 dd $15 \mathrm{mg}$ als aanvullende behandeling voor de hik en dit leidde tot verbetering. ${ }^{6}$

Of het tegelijkertijd optreden van de hik en COVID-19 berust op toeval of op een werkelijke associatie tussen ziekte en symptoom, is op basis van deze gevalsbeschrijvingen moeilijk te zeggen. Een mogelijke pathofysiologische verklaring is te vinden in een verslag uit 2018 over een Griekse patiënt die de hik had als symptoom van een pneumonie. ${ }^{7}$ De auteurs schrijven dat bij alle 4 de tot dan toe bekende patiënten met de hik bij een pneumonie de onderkwab van de long was aangedaan. De gedachte is dat het infiltraat directe prikkeling van het diafragma kan geven.

\section{DIAGNOSTIEK BIJ PERSISTERENDE HIK}

Bij een persisterende hik moet naar eventuele onderliggende pathologie worden gezocht. Dit kan een uitdaging zijn. Vraag in de anamnese naar:

- ernst en duur van de hik

- of de hik ook tijdens de slaap optreedt (dit wijst vaak op een organische oorzaak) ${ }^{3}$

- beïnvloedende factoren

- de medische voorgeschiedenis, inclusief eerdere hikepisodes

- medicatiegebruik; intoxicaties en bijkomende klachten op basis van een tractusanamnese

Het lichamelijk onderzoek levert niet altijd een aanknopingspunt op. Schenk in het bijzonder aandacht aan:

- tekenen van infectie (koorts)

- kno-gebied

- hals

n thorax

- abdomen

- neurologische afwijkingen

Aanvullend onderzoek wordt op indicatie verricht. Het kan bestaan uit laboratoriumonderzoek (elektrolyten, lever- en pancreasenzymen, glucose, nierfunctie, infectiewaarden), zo nodig uitgebreid met een gastroscopie, X-thorax, CT-scan van thorax, abdomen, hals of hersenen of een MRI van de hersenen. ${ }^{1}$ De landelijke richtlijn Hik bevat hiervoor een stappenplan. ${ }^{3}$

Het is de vraag of het beloop bij onze patiënt anders was geweest als we in een eerder stadium lichamelijk onderzoek hadden ingezet. Een belangrijke les is wel dat je als huisarts bij herhaald contact met dezelfde patiënt de situatie toch opnieuw moet inschatten en je differentiaaldiagnose moet heroverwegen door de patiënt zelf te zien. Ook bij een ogenschijnlijk onschuldig symptoom kan het beloop grillig zijn.

\section{CONCLUSIE}

Persisterende hik kan een uiting zijn van een (ernstige) onderliggende aandoening met een brede differentiaaldiagnose. Niet 
altijd wordt de oorzaak gevonden. De hik lijkt ook een vroeg symptoom van een SARS-CoV-2-infectie, in onze casus was de hik aanvankelijk zelfs het enige symptoom. Waarop een mogelijke associatie tussen COVID-19 en de hik zou kunnen berusten, moet nog verder worden uitgezocht.

\section{LITERATUUR}

1. Steger M, Schneemann M, Fox M. Systemic review: the pathogenesis and pharmacological treatment of hiccups. Aliment Pharmacol Ther 2015;42:1037-50.

2. Van Heuven CG, Eekhof JA, Knuistingh Neven A. De hik. Huisarts Wet 2006;49:276-8.

3. Zylicz Z, De Graeff A, Hesselmann GM. Richtlijn hik, versie 2.0. Utrecht: IKNL, 2009. www.oncoline.nl, geraadpleegd februari 2021.

4. Prince G, Sergel M. Persistent hiccups as an atypical presenting complaint of COVID-19. Am J Emerg Med 2020;38:1546.e5-6.
5. Boland-Rodríguez E, Estrada-Jaime MA, Soto-Salazar LG. Singultus as initial symptom of infection due to SARS-CoV-2. Med Int Mex 2020;36:745-8.

6. Bakheet N, Fouad R, Kassem AM, Hussin W, et al. Persistent hiccup: a rare presentation of COVID-19. Respir Investig 2021;59:263-5.

7. Karakonstantis S, Pitsigavdaki S, Korela D, et al. Lower lobe pneumonia presenting as singultus (hiccups). Caspian J Intern Med 2018;9:403-5.

Knijp J, Prins FM. De hik als vroeg symptoom bij COVID-19. Huisarts Wet 2021;64:D0l:10.1007/s12445-021-1105-3.

Stichting Amsterdamse Gezondheidscentra, locatie Osdorp: J. Knijp, anios Huisartsgeneeskunde [thans arts-onderzoeker Vasculaire geneeskunde, Amsterdam UMC locatie AMC], jannetknijp92@gmail.com; F.M. Prins, huisarts.

Mogelijke belangenverstrengeling: niets aangegeven. 